\title{
Instrumental Evaluation of Flesh Texture in Apple Cultivars
}

\author{
Kyohei Kanamaru $^{1 *}$, Kaoru Kohyama ${ }^{2}$, Kunihiko Konisho $^{1}$ and Katsuaki Izumi ${ }^{1}$ \\ ${ }^{1}$ Nagano Prefectural Fruit Tree Experiment Station, Suzaka 382-0072, Japan \\ ${ }^{2}$ Food Research Institute, National Agriculture and Food Research Organization, Tsukuba 305-8642, Japan
}

We used instruments to analyze the texture of compressed samples obtained from the equatorial portion of apples cut in radial and tangential directions. The flesh firmness evaluation of apples using a penetrometer (Magness-Taylor type) showed a year-to-year correlation, and this was highly correlated with mechanical values, including maximum force $(\mathrm{N})$ evaluated using two instruments in both the radial and tangential directions. On the other hand, no significant relationship between the mechanical values obtained from the instruments and the sensory test results of flesh texture was observed. We adopted a crispness index (CI) value to characterize the mechanical response during the penetration test. The CI value was not correlated with most of the mechanical parameters in the Rheoner analysis. Additionally, we used a TA.XTplus texture analyzer to obtain mechanical and acoustic responses during the penetration test. The maximum and average acoustic pressures $(\mathrm{dB})$ were not correlated with the mechanical parameters. There was a significant correlation between the acoustic profiles and the $\mathrm{CI}$ values obtained from the instruments. These results revealed that the CI and acoustic profiles were physical responses that differed from mechanical ones when measuring the flesh texture of apple fruit. In this study, the CI and acoustic pressure were associated with the sensory test results of flesh texture, suggesting that these parameters were effective for objectively evaluating the flesh texture of apples. The cultivars and selections evaluated as having high crunchiness by sensory test showed relatively high $C I$ values and acoustic pressure. In addition, the CI value showed a significant year-to-year correlation $(r=0.68 * *)$, implying that it was one of the genetic characteristics responsible for the flesh texture of apples.

Key Words: acoustic pressure, anisotropy, crispness index, mechanical response.

\section{Introduction}

Texture is one of the qualities that determine the palatability of apple fruit. Therefore, improving the fruit texture is an important objective in apple breeding programs. Recently, many cultivars with desirable textures, such as crispness and crunchiness, have been developed worldwide (Brown and Maloney, 2013, 2018). For instance, 'Honeycrisp', developed by Minnesota University, has been popular in the global market because consumers like its texture (Luby and Bedford, 1992). Some of the most preferred apple cultivars are exhibited in international trade fairs. 'WA38' developed by Washington State University (Evans et al., 2012) and

Received; October 8, 2020. Accepted; January 28, 2021.

First Published Online in J-STAGE on April 2, 2021.

No conflict of interest declared.

* Corresponding author (E-mail: kanamaru-kyohei-r@pref.nagano. lg.jp).
'Scilate' developed by Plant \& Food Research in New Zealand (Brown and Maloney, 2013, 2018) have attractive crispness and crunchiness qualities along with moderate firmness and high juiciness.

Generally, external appearance and taste are crucial palatability components taken into account when buying apples in Japan. Nakamura (2010) reported that Japanese consumers consider the texture when buying apples as the second most important criterion following sweetness. Apple cultivars recently developed in Japan have highly desirable flesh texture qualities. 'Shinano Gold', which was developed in our breeding program, has a desirable texture, is juicy, and has long storability (Komatsu, 2018; Komatsu et al., 2000). Owing to its desirable qualities, 'Shinano Gold' was launched in the global market for cultivation and commercialization under the simple name 'YELLO'TM' (Brown and Maloney, 2018; Komatsu et al., 2019).

Some reports have indicated that climate change affects the textural properties of apples. Sugiura et al. 
(2013) provided evidence that the taste and textural properties of apples have changed owing to recent global warming, for example, in terms of decreased firmness. In addition, a recent study reported that the flesh firmness of the apple cultivar 'Fuji' tended to decrease in fruit cultivated in greenhouses compared to fruit cultivated in an experimental field in Nagano prefecture (Ichikawa et al., 2018). Therefore, improvement in textural properties is necessary not only to satisfy consumer preference, but also to adapt to climate change.

The general scheme of apple breeding and the textural properties of apples are mainly determined through sensory evaluation by breeders. For instance, the textural properties of flesh are crispness, crunchiness, softness, mealiness and so on. On the other hand, the textural properties of apple cultivars and selections are also continuous variables and quantitative traits. In addition, new apple cultivars with crispness and crunchiness have recently been developed. Therefore, it is necessary to objectively quantify the textural properties in order to effectively select desirable seedlings for apple breeding. Moreover, it is necessary to characterize the genetic background responsible for the textural properties of apples.

A penetrometer (Magness-Taylor type) with a $7 / 16$ inch convex probe is commonly used to evaluate the flesh firmness of apples. However, it is not generally enough to perform a sensory evaluation. One of the reasons for this is it is only capable of obtaining the maximum force during penetration.

Some previous studies used a Rheoner II Creep Meter commercialized by Yamaden Co., Ltd., Tokyo, Japan (Horie et al., 2004; Masumoto et al., 2018; Yoshikawa et al., 2009). They defined the crispness index (CI) value by the sum of absolute values of the secondary differentiation derived from mechanical signals during penetration. Therefore, the CI value corresponds to the degree of amplitude of the mechanical response. This was useful for evaluating the crispness of cucumbers (Horie et al., 2004) and persimmons (Matsumoto et al., 2018). Horie et al. (2004) also suggested that CI values may be useful for evaluating the textural properties of other fruits, including apples.

Instruments that gather both mechanical and acoustic responses during penetration were also examined in previous studies (Costa et al., 2011, 2012; Zdunek et al., 2010a, b). Zdunek et al. (2010a, b) concluded that acoustic profiles were suitable to evaluate the sensory variation of apple texture, with instruments developed for their studies using a laboratory-made penetration machine with a contact acoustic emission detector. Costa et al. (2012) characterized the textural properties of fruit at harvest and postharvest using more than 80 apple cultivars and a TA.XTplus texture analyzer with an Acoustic Envelop Detector device (Stable Micro Systems Ltd., Surrey, UK). The authors suggested that the storage index derived from mechanical and acoustic responses was suitable for assessing storage potential.

Generally, the textural properties of fruits and vegetables are affected by physical characteristics such as cell structure and water content. It has been reported that the mechanical properties of apple flesh depend on the structural anisotropy of the parenchyma (Khan and Vincent, 1993a, b). Apple flesh is classified into two types of anisotropy. Radial and tangential types are consistent with a parallel orientation to rows of cylindrical flesh cells and horizontal and vertical orientations to rows of cylindrical flesh cells, respectively. At the equatorial portion of the apple fruit, the compression exerted from the outside to the center that is similar to that exerted by a penetrometer, is radial, and the compression that is parallel to the fruit axis is tangential. The tangential direction exhibits a higher force than the radial direction (Khan and Vincent, 1993a, b; Kohyama et al., 2017). Therefore, the radial or tangential nature of the penetration direction in the apple flesh parenchyma should also be considered when investigating textural properties.

The objective of this study was to characterize the flesh texture of apple cultivars originating mainly in Japan. We used two different methods to objectively investigate the textural properties of apples and discuss the relationships between the instrumental parameters and the results of sensory evaluations performed to clearly elucidate the most useful method for assessing the flesh texture of apples.

\section{Materials and Methods}

\section{Plant materials}

Twenty-one apple cultivars and selections, mainly developed in Japan, including some cultivars of foreign origin, were used for the instrumental evaluation of flesh texture. We collected fruit samples from each cultivar and selection based on the harvest period of an average year and measured maturity indices including background color of skin, starch disappearance and flesh firmness. 1 'Wasefuji', 2 'Toki', 3 'Akibae', 4 'Shinano Sweet', and 5 'Golden Delicious' were harvested in early-October, 6 'Morinokagayaki', 7 'Haruka', 8 'Aori15', and 9 'Starking Delicious' were harvested in mid-October, 10 'Shinano Gold', 11 'Selection A', 12 'Aikanokaori', 13 'Kinsei', 14 'Selection B', and 15 'Gunma Meigetsu' were harvested in late-October, 16 'Shinano Hoppe', 17 'Fuji', 18 'Granny Smith', 19 'Slim Red', 20 'Braeburn', and 21 'Orin' were harvested in early-November. All plant materials were cultivated in the experimental field of Nagano Prefectural Fruit Tree Experiment Station (Suzaka, Nagano, Japan) in 2017 and 2018. The fruit samples were kept in cold storage $\left(2-5^{\circ} \mathrm{C}\right)$ for freshness retention, and were used for instrumental evaluation less than two weeks after harvest. They were maintained overnight at room temperature $\left(20-25^{\circ} \mathrm{C}\right)$ prior to the instrumental evaluation. 
Analysis of flesh firmness using a penetrometer

Five fruits from each cultivar and selection were used for instrumental analysis. Each of the fruit samples was weighed and the sunshine- and shade-facing surfaces of the equatorial portion were removed. The firmness $(\mathrm{N})$ of the two portions was investigated using a MagnessTaylor penetrometer equipped with a probe of approximately 7/16-inches in diameter. The firmness of each fruit was determined by the mean value obtained from the second penetration tests. The penetration tests of the whole fruit could only be conducted in the radial direction.

\section{Preparation of flesh specimens}

We prepared flesh specimens for penetration along the radial and tangential directions according to the methods of Khan and Vincent (1993a, b) and Kohyama et al. (2017). Radial is the direction along the cell rows and tangential is the direction that forms a right angle to the cell rows (Khan and Vincent, 1993a, b). The specimens were prepared from the equatorial portions of fruit that were cut in round slices of approximate 20$\mathrm{mm}$ thickness after the penetrometer test. Three radial and three tangential compression specimens were prepared in the form of rectangular blocks, which were approximately $20 \mathrm{~mm}$ in diameter and $10 \mathrm{~mm}$ thick, and used for instrumental evaluation (Fig. 1).

\section{Instrumental evaluation of flesh texture}

We used two types of commercial instruments. In the first method, a total of 21 cultivars and selections were used for the penetration test in 2017 using a Rheoner RE2-33005B creep meter (Yamaden) at the Food Research Institute, NARO (Tsukuba, Ibaraki, Japan). This instrument was equipped with a load cell of $200 \mathrm{~N}$. Three-millimeter flat head probes penetrated the flesh specimens at a test speed of $1 \mathrm{~mm} \cdot \mathrm{s}^{-1}$, compressing the samples until a final deformation of $80 \%$ of the original height was reached. The instrument acquired mechanical responses every $0.02 \mathrm{~s}$, as this allowed acquisition of approximately 450 data points until the final deformation. The mechanical responses were characterized by breaking force $(\mathrm{N})$ and maximum force $(\mathrm{N})$ (Fig. 2). The secondary differentiation was calculated using the values (approximately 350 data points) of force between deformations of approximately $10 \%$ and $80 \%$ of the original height. The crispness index (CI) was defined as the sum of absolute values of the secondary differentiation of force according to Horie et al. (2004). The CI was calculated with following equation, $\mathrm{CI}=$ $\Sigma\left|2 F_{t}-\left(F_{t-1}+F_{t+1}\right)\right|$, where $F_{t}$ is force value at time $t$, $F_{t-1}$ and $F_{t+1}$ are force values at $0.02 \mathrm{~s}$ before and after time $t$, respectively. In 2018, 18 cultivars and selections except for 4 'Shinano Sweet', 6 'Morinokagayaki', and 12 'Aikanokaori' were used for textural analysis using a Rheoner RE2-33005C (Yamaden) with the same method mentioned above at Nagano Prefectural Fruit Tree Experiment Station.

In the second method, 18 cultivars and selections except for 19 'Slim Red', 20 'Braeburn' and 21 'Orin' were analyzed in 2017 using a TA.XTplus texture analyzer at the Food Research Institute. This instrument was equipped with a load cell of $50 \mathrm{~N}$ and an Acoustic

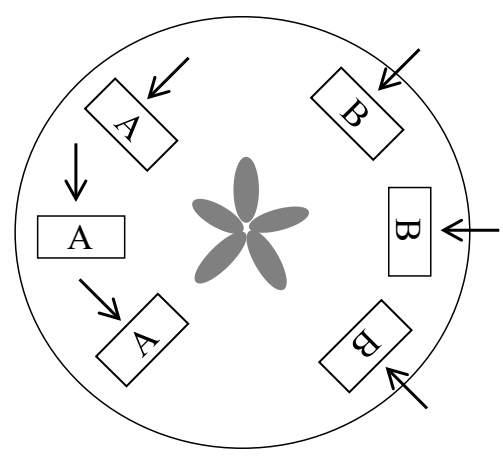

Fig. 1. Diagram of flesh specimen preparation. Overview of the equatorial portion of apple fruit. The center shows the core. Rectangle A shows the specimen penetrated in a forward tangential direction, and $\mathrm{B}$ is the forward radial direction. Arrows show the penetration direction.
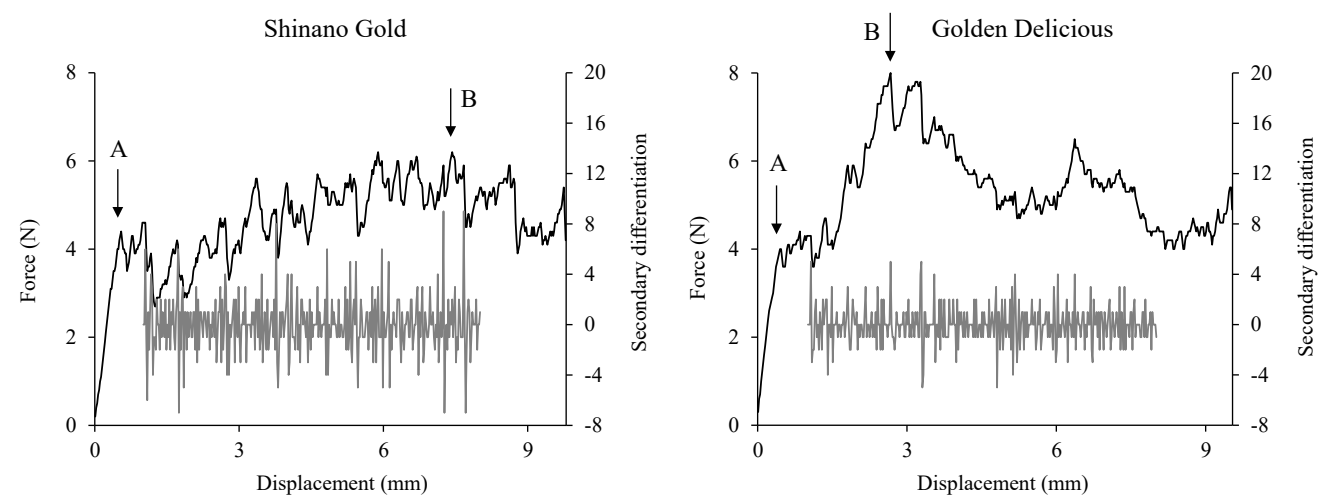

Fig. 2. Mechanical and secondary differentiation profiles in the tangential direction of two apple cultivars, 'Shinano Gold' and 'Golden Delicious', using the Rheoner RE2-33005B in 2017. The black and gray lines indicate the force (N) and the secondary differentiation displacement profile, respectively. A and B indicate the breaking force $(\mathrm{N})$ and maximum force $(\mathrm{N})$, respectively. 

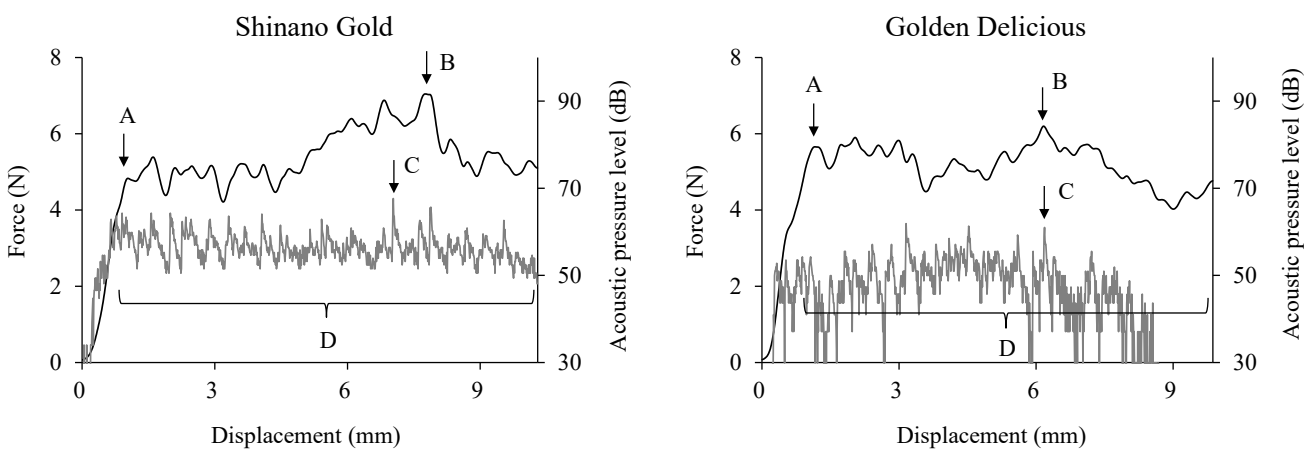

Fig. 3. Mechanical and acoustic profile during penetration in the tangential direction of two apple cultivars, 'Shinano Gold' and 'Golden Delicious' obtained by a TA.XTplus Texture Analyzer with a 3-mm cylindrical probe at $5 \mathrm{~mm} \cdot \mathrm{s}^{-1}$. The black and gray lines indicate the force $(\mathrm{N})$ and the acoustic $(\mathrm{dB})$ displacement profile, respectively. A, B, C, and D indicate the breaking force $(\mathrm{N})$, maximum force $(\mathrm{N})$, maximum acoustic pressure $(\mathrm{dB})$, and average acoustic pressure $(\mathrm{dB})$, respectively.

Envelope Detector device, which was placed approximately $20 \mathrm{~mm}$ away from the sample in order to gain a mechanical and acoustic response simultaneously. A cylindrical probe (3-mm diameter) penetrated the flesh specimen at a constant speed of $5 \mathrm{~mm} \cdot \mathrm{s}^{-1}$ until the final deformation was $90 \%$ of the original height, as described by Kohyama et al. (2017). A penetration test was conducted with a constant speed of $5 \mathrm{~mm} \cdot \mathrm{s}^{-1}$ according to Costa et al. (2011), because a slow speed of $1 \mathrm{~mm} \cdot \mathrm{s}^{-1}$, which was the same as that used in Rheoner, yielded weak acoustic responses in some preliminary tests. The analyzer acquired mechanical and acoustic responses every $0.002 \mathrm{~s}$. We obtained approximately 1,000 data points in approximately $2 \mathrm{~s}$ until the final deformation. Other conditions were as described by Costa et al. (2011). The mechanical responses were characterized by breaking force $(\mathrm{N})$ and maximum force $(\mathrm{N})$, and the acoustic responses were characterized by the maximum acoustic pressure $(\mathrm{dB})$ and average acoustic pressure $(\mathrm{dB})$ between the breaking force point and the final deformation of penetration (Fig. 3). The secondary differentiation was calculated using the values (approximately 900 data points) of force between deformations of approximately $10 \%$ and $90 \%$ of the original height. CI was also defined according to the first method with a slight modification in which $F_{t-1}$ and $F_{t+1}$ were force values at $0.002 \mathrm{~s}$ before and after time $t$, respectively.

\section{Sensory test of flesh texture}

All fruit materials that remained after preparing flesh specimens for instrumental evaluation were tested by the author. Directional differences of specimens were not considered in the sensory test. As each fruit may have a different texture, all fruit samples were evaluated by an expert. The grade of flesh texture was classified into five degrees by comprehensively evaluating the firmness, juiciness and flesh density. Grade 5 corresponded to the most desirable level of texture, corresponding to high crunchiness owing to moderate firmness and high juiciness, grade 4 represented a mod-

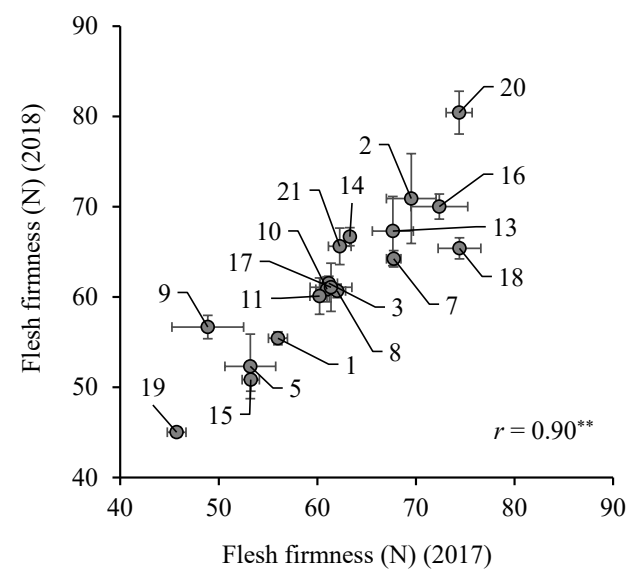

Fig. 4. Year-to-year correlation of the flesh firmness of 18 apple cultivars and selections using a penetrometer. Data are represented as means $\pm \mathrm{SE} \quad(\mathrm{n}=5)$. (1 'Wasefuji', 2 'Toki', 3 'Akibae', 5 'Golden Delicious', 7 'Haruka', 8 'Aori15', 9 'Starking Delicious', 10 'Shinano Gold', 11 'Selection A', 13 'Kinsei', 14 'Selection B', 15 'Gunma Meigetsu', 16 'Shinano Hoppe', 17 'Fuji', 18 'Granny Smith', 19 'Slim Red', 20 'Braeburn', and 21 'Orin'. 4 'Shinano Sweet', 6 'Morinokagayaki', and 12 'Aikanokaori' were included in 2017; their flesh firmness values were $55.5 \mathrm{~N}, 63.2 \mathrm{~N}$, and $56.8 \mathrm{~N}$, respectively)

erately high level, grade 3 represented the standard level, grade 2 represented a moderately low level, and grade 1 represented the worst textural level that was soft or mealy.

\section{Results}

\section{Flesh firmness distribution}

The flesh firmness of the 18 cultivars and selections ranged from $45.7 \mathrm{~N}$ to $74.4 \mathrm{~N}$ and from $45.0 \mathrm{~N}$ to $80.4 \mathrm{~N}$ in 2017 and 2018, respectively (Fig. 4). 'Slim Red' and 'Braeburn' had the lowest and highest firmness values, respectively, in both 2017 and 2018. The flesh firmness of the 18 cultivars showed a year-to-year correlation with a high correlation coefficient $(r=$ $\left.0.90^{* *}\right)$. There was no correlation between fruit weight 
and flesh firmness in either $2017\left(r=0.13^{\mathrm{NS}}\right)$ or 2018 $\left(r=0.061^{\mathrm{NS}}\right)$.

\section{Instrumental evaluation of flesh texture using a Rheoner RE2}

The breaking force $(\mathrm{N})$ results of the penetration test indicated the breaking point at which the probe broke the specimens was at a displacement of $0.54 \mathrm{~mm}$ for 'Shinano Gold' and $0.46 \mathrm{~mm}$ for 'Golden Delicious' (Fig. 2). Following the breaking force, the maximum force $(\mathrm{N})$, which was the maximum value obtained while compressing the flesh until the final deformation, was found at a displacement of $7.42 \mathrm{~mm}$ for 'Shinano Gold' and $2.66 \mathrm{~mm}$ for 'Golden Delicious'. The breaking force in 21 cultivars and selections ranged from $2.7 \mathrm{~N}$ to $5.9 \mathrm{~N}$ in the radial and from $2.7 \mathrm{~N}$ to $6.1 \mathrm{~N}$ in the tangential direction, respectively. 'Slim Red' and 'Braeburn' had the lowest and highest values, respectively, in both directions (data not shown). The maximum force in 21 cultivars and selections ranged from 4.6 N in 'Gunma Meigetsu' to $8.3 \mathrm{~N}$ in 'Granny Smith' in the radial direction, and from $5.2 \mathrm{~N}$ in 'Wasefuji' to $9.8 \mathrm{~N}$ in 'Morinokagayaki' in the tangential direction (data not shown). The mechanical response parameters, such as breaking force, maximum force, and flesh firmness, were highly correlated with each other (Table 1).

Secondary differentiation was calculated using the mechanical force values as shown in Figure 2 with a gray line. The increase and decrease in amplitude from the mechanical force $(\mathrm{N})$ during the penetration test corresponded to the degree of secondary differentiation. Although 'Golden Delicious' had a higher maximum force value compared to 'Shinano Gold', the secondary differentiation value of 'Shinano Gold' was higher than that of 'Golden Delicious' (Fig. 2). This resulted in a high CI value (50.9) in 'Shinano Gold' compared to 'Golden Delicious' $(\mathrm{CI}=35.9)$ in the tangential direction (Fig. 5). 'Starking Delicious' had the lowest value $(\mathrm{CI}=30.6)$, and 'Granny Smith', 'Selection A', 'Akibae' and 'Selection B' showed high values of 59.4,

Table 1. Correlation coefficients of the parameters obtained by the Rheoner RE2-33005B.

\begin{tabular}{lccl}
\hline \hline & $\begin{array}{c}\text { Breaking force } \\
(\mathrm{N})\end{array}$ & $\begin{array}{c}\text { Max. force } \\
(\mathrm{N})\end{array}$ & CI value \\
\hline Flesh firmness $(\mathrm{N})$ & $0.78^{* *}$ & $0.83^{* *}$ & $0.45^{*}$ \\
\hline Breaking force $(\mathrm{N})$ & $\left(0.90^{* *}\right)$ & $0.76^{* *}$ & 0.24 \\
& & $0.88^{* *}$ & 0.25 \\
\hline \multirow{2}{*}{ Max. force $(\mathrm{N})$} & & $\left(0.90^{* *}\right)$ & $0.52^{*}$ \\
\hline CI value & & & 0.44 \\
\hline
\end{tabular}

The upper values indicate data from the radial direction, and the lower values indicate data from the tangential direction for each parameter. The data in parentheses indicate values between the radial and tangential directions. ${ }^{* *}$ and $*$ indicate significant differences at the $1 \%$ and $5 \%$ levels, respectively.
59.3, 58.6, and 57.2, respectively, in the tangential directions. The CI values in 21 apple cultivars and selections in the tangential direction were correlated with those in the radial direction in 2017 (Table 1). There were no strong correlations between the $\mathrm{CI}$ value and mechanical force parameters, although the CI value was moderately correlated with flesh firmness and maximum force in the radial direction (Table 1).

Eighteen apple cultivars and selections were examined for textural analysis using a RE2-33005C creep meter (Yamaden) at the Nagano Prefectural Fruit Tree Experimental Station in 2018. The CI values ranged from 38.4 to 69.1 in the tangential direction (Fig. 5), they were correlated with those in the radial direction $\left(r=0.73^{* *}\right)$. 'Kinsei' had the lowest value in both directions. 'Selection B' and 'Orin' had the highest CI values in the radial and tangential directions, respectively. There was a significant year-to-year correlation, although the CI values of some cultivars and selections, such as 'Starking Delicious', Braeburn', and 'Orin' were different depending on the year. The maximum force and breaking force in the radial direction showed significant year-to-year correlation with $r=0.81^{* *}$ and $r=0.81^{* *}$, respectively. Additionally, the maximum force and breaking force in the tangential direction showed significant year-to-year correlation with $r=$ $0.71^{* *}$ and $r=0.76^{* *}$, respectively (data not shown).

\section{Instrumental evaluation of flesh texture using TA.XTplus}

The TA.XTplus texture analyzer allowed us to obtain mechanical and acoustic responses during the penetration test of the apple flesh specimens, as shown in

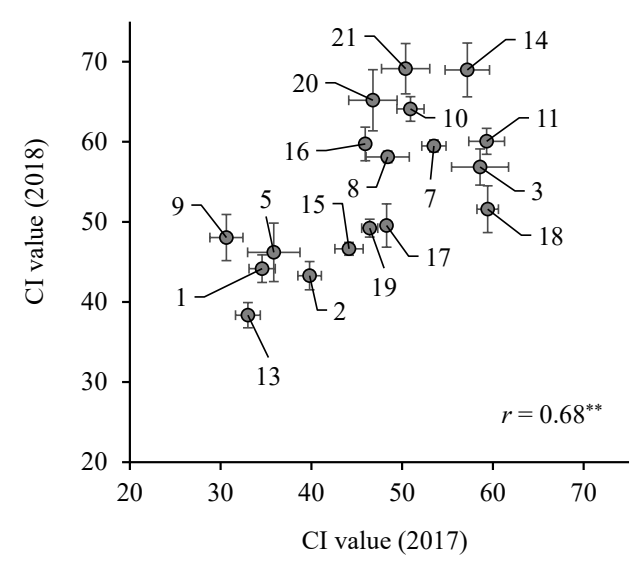

Fig. 5. Year-to-year correlations of the CI values obtained from the tangential direction of 18 apple cultivars. Data are represented as means $\pm \mathrm{SE}(\mathrm{n}=5)$. (1 'Wasefuji', 2 'Toki', 3 'Akibae', 5 'Golden Delicious', 7 'Haruka', 8 'Aori15', 9 'Starking Delicious', 10 'Shinano Gold', 11 'Selection A', 13 'Kinsei', 14 'Selection B', 15 'Gunma Meigetsu', 16 'Shinano Hoppe', 17 'Fuji', 18 'Granny Smith', 19 'Slim Red', 20 'Braeburn', and 21 'Orin'. 4 'Shinano Sweet', 6 'Morinokagayaki', and 12 'Aikanokaori' were included in 2017; their CI values in the tangential direction were $41.4,52.1$, and 48.7 , respectively) 
Figure 3. Following the breaking force at the displacement of $0.98 \mathrm{~mm}$ of 'Shinano Gold' and $1.10 \mathrm{~mm}$ of 'Golden Delicious', the force and acoustic pressure (dB) reached their maximum values during flesh compression and until the final deformation.

The maximum force values in the radial and tangential directions ranged from $5.1 \mathrm{~N}$ to $8.2 \mathrm{~N}$ and from $5.3 \mathrm{~N}$ to $8.9 \mathrm{~N}$, respectively in 18 apple cultivars and selections (Fig. 6). 'Granny Smith' and 'Starking Delicious' had the highest and lowest maximum force values, respectively, in the radial and tangential directions (Fig. 6). In addition, the maximum force of 17 cultivars and selections except for 'Shinano Gold' $(6.51 \mathrm{~N}$ in the radial and 6.45 in the tangential direction) tended to be relatively higher in the tangential direction than in the radial direction. 'Kinsei' and 'Shinano Hoppe' showed the smallest $(0.14 \mathrm{~N})$ and largest $(1.19 \mathrm{~N})$ differences between tangential and radial, respectively. The mechanical response parameters, such as breaking force, maximum force, and flesh firm- ness, were highly correlated with each other, regardless of the directional differences of the specimens (Table 2). The CI was also determined, and its value ranged from 1.64 to 3.39 in the tangential direction (data not shown), and was correlated with that in the radial direction (Table 2). 'Staking Delicious', 'Wasefuji' and 'Kinsei' showed low CI values of 1.64, 1.83, and 1.94, respectively, and 'Granny Smith', 'Selection B', 'Selection A' and 'Akibae' showed high CI values of $3.39,3.02,2.99$, and 2.87 , respectively, in the tangential direction. The TA.XTplus texture analyzer indicated a moderate to high significant correlation between the $\mathrm{CI}$ value and all parameters in both directions (Table 2). The CI values obtained from the two instruments were highly correlated with each other $(r=0.92 * *$ in the radial direction and $r=0.93^{* *}$ in the tangential direction); however, the absolute CI values obtained from the two instruments were different.

Varietal differences were observed in terms of acoustic responses during penetration. The acoustic pressure
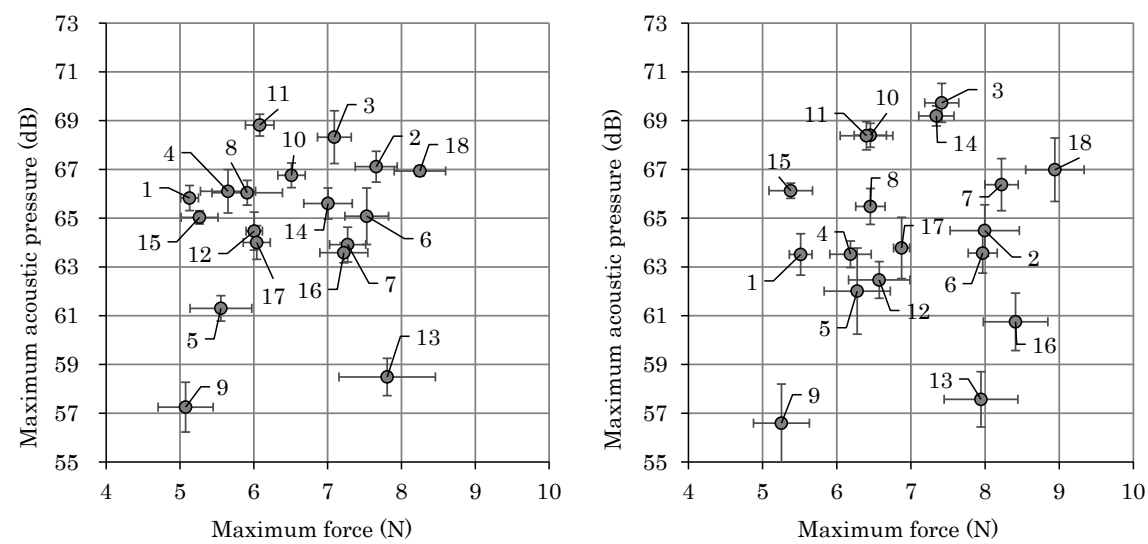

Fig. 6. Relationship between the maximum force value and acoustic pressure value in the radial (left) and tangential (right) directions. Data are represented as means $\pm \mathrm{SE}(\mathrm{n}=5)$. (1 'Wasefuji', 2 'Toki', 3 'Akibae', 4 'Shinano Sweet', 5 'Golden Delicious', 6 'Morinokagayaki', 7 'Haruka', 8 'Aori15', 9 'Starking Delicious', 10 'Shinano Gold', 11 'Selection A', 12 'Aikanokaori', 13 'Kinsei', 14 'Selection B', 15 'Gunma Meigetsu’, 16 'Shinano Hoppe’, 17 'Fuji’, and 18 ‘Granny Smith')

Table 2. Correlation coefficients of the parameters obtained by TA.XTplus analysis

\begin{tabular}{|c|c|c|c|c|c|}
\hline & $\begin{array}{c}\text { Breaking force } \\
(\mathrm{N})\end{array}$ & $\begin{array}{l}\text { Max. force } \\
(\mathrm{N})\end{array}$ & $\begin{array}{l}\text { Max. acoustic } \\
\text { pressure }(\mathrm{dB})\end{array}$ & $\begin{array}{l}\text { Average acoustic } \\
\text { pressure }(\mathrm{dB})\end{array}$ & $\mathrm{CI}$ value \\
\hline Flesh firmness $(\mathrm{N})$ & $0.90 * *$ & $0.90 * *$ & 0.26 & 0.18 & $0.56^{*}$ \\
\hline \multirow{2}{*}{ Breaking force $(\mathrm{N})$} & \multirow{2}{*}{$(0.93 * *)$} & $0.90 * *$ & 0.21 & 0.11 & $0.58^{*}$ \\
\hline & & $0.95 * *$ & 0.09 & 0.07 & $0.55^{*}$ \\
\hline \multirow{2}{*}{ Max. force $(\mathrm{N})$} & & \multirow{2}{*}{$(0.96 * *)$} & 0.17 & -0.004 & $0.64 * *$ \\
\hline & & & 0.14 & 0.03 & $0.60 * *$ \\
\hline \multirow{2}{*}{ Max. acoustic pressure (dB) } & & & \multirow{2}{*}{$\left(0.86^{* *}\right)$} & $0.92 * *$ & $0.72 * *$ \\
\hline & & & & $0.91 * *$ & $0.76 * *$ \\
\hline \multirow{2}{*}{ Average acoustic pressure $(\mathrm{dB})$} & & & & \multirow{2}{*}{$\left(0.96^{* *}\right)$} & $0.59 *$ \\
\hline & & & & & $0.62 * *$ \\
\hline CI value & & & & & $(0.95 * *)$ \\
\hline
\end{tabular}

The upper values indicate data from the radial direction and the lower values indicate data from the tangential direction for each parameter. The data in parentheses indicate values between the radial and tangential directions. ** indicates significant differences at the $1 \%$ level. 
of 'Shinano Gold' was higher than $50 \mathrm{~dB}$ from the breaking force point until the final deformation, and the maximum acoustic pressure $(67.6 \mathrm{~dB})$ was observed at a displacement of $6.98 \mathrm{~mm}$ (Fig. 3). On the other hand, 'Golden Delicious' was less noisy; its acoustic pressure was a little below $30 \mathrm{~dB}$ until the final deformation (Fig. 3). The maximum acoustic pressure of 'Starking Delicious' had the lowest value in the radial $(57.3 \mathrm{~dB})$ and tangential directions (56.6 dB) (Fig. 6). 'Selection $A^{\prime}$ ' had the highest maximum acoustic pressure value $(68.8 \mathrm{~dB})$ in the radial direction (Fig. 6) and the highest average acoustic values in the radial and tangential directions (data not shown). 'Akibae' had the highest maximum acoustic pressure value $(69.7 \mathrm{~dB})$ in the tangential direction (Fig. 6). In addition, the two acoustic parameters were highly correlated with each other, regardless of directional differences (Table 2). The two acoustic parameters were also positively correlated with the CI values in both directions. Moreover, there was no significant correlation between the mechanical response parameters and acoustic pressure.

\section{Relationships between instrumental parameters and} sensory test of flesh texture

The flesh texture grade was classified into five degrees by comprehensive evaluation. 'Shinano Gold', 'Selection A', and 'Selection B' were classified into grade 5 because they exhibited high juiciness and moderate firmness (Fig. 7). The texture of 'Granny Smith' was very firm and crunchy, but it was partially chewy because of fibrousness and roughness. The textures of 'Shinano Hoppe' and 'Braeburn' were firm with dense and moderate juiciness, resulting in moderate crispness. 'Shinano Sweet', 'Aikanokaori', 'Gunma Meigetsu', and 'Fuji' were moderately firm and juicy, resulting in a smooth texture. Although 'Slim Red' showed the lowest value of flesh firmness $(\mathrm{N})$, its texture was moderately crunchy owing to its juiciness and roughness. 'Wasefuji', 'Golden Delicious', and 'Starking Delicious' were classified with a low texture grade because of softness and mealiness. Although 'Kinsei' had moderate firmness, it was classified as grade 2 due to a low level of crunchiness caused by a low degree of juiciness.

No significant relationships between flesh firmness and the sensory test results of flesh texture were observed $\left(r=0.28^{\mathrm{NS}}\right)$ in 2017 (Table 3) or $\left(r=0.21^{\mathrm{NS}}\right)$ in 2018 (data not shown). In addition, there were no significant correlations between mechanical responses such as breaking force and maximum force obtained by the Rheoner RE2-33005B or TA.XTplus texture analyzer and the sensory test flesh texture results. On the other hand, the sensory test results were significantly correlated with the CI values and the acoustic responses in
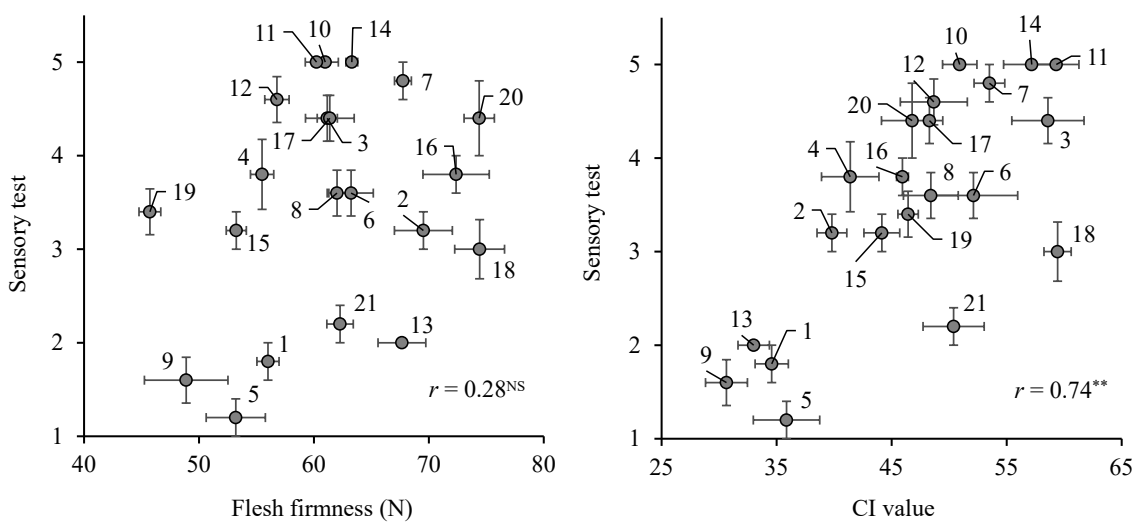

Fig. 7. Relationship between flesh firmness from a penetrometer and sensory test (left), between the CI value in the tangential direction from the Rheoner and sensory test (right) in 2017. Data are represented as means $\pm \mathrm{SE}(\mathrm{n}=5)$. (1 'Wasefuji', 2 'Toki', 3 'Akibae', 4 'Shinano Sweet', 5 'Golden Delicious', 6 'Morinokagayaki', 7 'Haruka', 8 'Aori15', 9 'Starking Delicious', 10 'Shinano Gold', 11 'Selection A', 12 'Aikanokaori', 13 'Kinsei', 14 'Selection B', 15 'Gunma Meigetsu', 16 'Shinano Hoppe', 17 'Fuji', and 18 'Granny Smith', 19 'Slim Red', 20 'Braeburn', and 21 'Orin')

Table 3. Correlation coefficients between the parameters and sensory flesh texture test results in 2017.

\begin{tabular}{|c|c|c|c|c|c|c|c|c|c|}
\hline Instrument & Penetrometer & & Rheoner RE2 & & & & TA.XT plus & & \\
\hline Parameter & Firmness & $\begin{array}{l}\text { Breaking } \\
\text { force }(\mathrm{N})\end{array}$ & $\begin{array}{l}\text { Max. force } \\
(\mathrm{N})\end{array}$ & CI value & $\begin{array}{l}\text { Breaking } \\
\text { force }(\mathrm{N})\end{array}$ & $\begin{array}{l}\text { Max. force } \\
\text { (N) }\end{array}$ & $\begin{array}{l}\text { Max. acoustic } \\
\text { pressure }(\mathrm{dB})\end{array}$ & $\begin{array}{c}\text { Average } \\
\text { acoustic } \\
\text { pressure }(\mathrm{dB})\end{array}$ & CI value \\
\hline \multirow{2}{*}{ Correlation coefficient } & \multirow{2}{*}{0.28} & 0.13 & 0.28 & $0.67 * *$ & 0.28 & 0.24 & $0.62 * *$ & $0.62 * *$ & $0.67 * *$ \\
\hline & & 0.21 & 0.26 & $0.74 * *$ & 0.26 & 0.25 & $0.68 * *$ & $0.69 * *$ & $0.65 * *$ \\
\hline
\end{tabular}

The upper values indicate data from the radial direction and the lower values indicate data from the tangential direction for each parameter. ** indicates significant differences at the $1 \%$ level. 
the radial and tangential directions (Fig. 7; Table 3).

\section{Discussion}

The flesh texture of apple fruit is one of the factors that influence consumer preference. We have been breeding apples with excellent flesh characteristics, such as crispness and crunchiness, using subjective sensory evaluations by breeders, but there is no way to objectively evaluate flesh texture. Moreover, there is limited information on the genetic variability of flesh texture in Japanese apple cultivars. Therefore, we analyzed flesh texture using instruments and determined the relationship between instrumental parameters and the sensory test results. In the present study, we graded textural properties through a sensory test created by the author who had been in charge of apple breeding at the experimental station. This expert was capable of evaluating precisely and comprehensively textural property differences in order to quantify breeders' sensory evaluations of the selection and to characterize the genetic background as it relates to texture.

\section{Instrumental evaluation of flesh texture}

We used a penetrometer (Magness-Taylor), as it is the most widespread tool to evaluate flesh firmness. Differences in the flesh firmness of 18 varieties and selections were observed in 2017 and 2018 (Fig. 4), indicating that flesh firmness is a genetic characteristic of each cultivar and selection. Tazawa et al. (2020) reported that flesh firmness in 19 Japanese apple cultivars showed high broad sense heritability $\left(h_{B}{ }^{2}=0.86\right)$. On the other hand, it was considered that the MagnessTaylor pressure tester was not effective in evaluating the gustatory qualities of flesh texture because there was no correlation between the flesh firmness and sensory test results (Table 3). For example, 'Shinano Hoppe' is known to be firmer compared to 'Fuji' and other Japanese apple cultivars (Kanamaru et al., 2016), but its textural property was around the standard level compared to 'Shinano Gold', 'Selection A', and 'Selection B', that had moderate firmness (Fig. 7). The penetrometer generally only allows measurement of the maximum load during the penetration test, which is suitable for evaluating the degree of fruit maturity and firmness.

We used two types of commercial instruments to evaluate the textural properties of apple flesh. In the first method, we analyzed flesh specimens using a Rheoner RE2-33005B in 2017, which was incapable of obtaining an acoustic response. We obtained not only the mechanical response, but also defined the CI value, which was calculated by the sum of absolute values of the mechanical value secondary differentiation. In previous studies, CI was useful for evaluating the flesh texture of cucumbers (Horie et al., 2004) and persimmons (Masumoto et al., 2018). These studies showed that the CI value is a parameter that differs from mechanical firmness. Masumoto et al. (2018) concluded that CI allows for the objective evaluation of the degree of crispness of persimmon fruit. Chang et al. (2018) observed the highest correlations between force-linear distance (the total length of force-distance curve) and crispness. It is considered that the degree of force-linear distance corresponds to the degree of amplitude of the mechanical response. That is, a larger amplitude of mechanical force leads to a higher CI value regardless of the degree of mechanical firmness. Our results also suggested that the mechanical firmness and CI value exhibit different flesh texture physical responses in apple fruit, although there were significant but low correlation coefficients in the radial direction (Table 1). For example, 'Slim Red' showed the lowest value of flesh firmness, but its texture was moderately crunchy; this may have been due to its moderate CI value (Fig. 7). Moreover, textural characteristics of 'Shinano Gold', 'Selection A', and 'Selection B' with high CI values indicated they were very crunchy despite having average firmness among the 21 cultivars and selections (Fig. 7). The degree of amplitude of the mechanical force obtained from the penetration test appeared to be related to crunchiness in the sensory test. On the other hand, 'Shinano Hoppe' was crispier than 'Slim Red' despite similar CI values; this may have been due to different levels of flesh firmness. It also implies that the degree of flesh firmness is needed to evaluate the crispness and crunchiness of apple flesh.

Although the CI values obtained from the two instruments were highly correlated with each other, the absolute CI values obtained from TA.XTplus were different from those obtained from the Rheoner. This could be attributed to the fact that the displacement values between $F_{t}$ and $F_{t-1}$ or $F_{t+1}$ from TA.XTplus were smaller than those from the Rheoner because TA.XTplus acquired 10 times more data samples than the Rheoner during the penetration test. Additionally, CI values obtained from TA.XTplus were moderately correlated with mechanical parameters (Table 2). It was considered that the CI value from TA.XTplus may be dependent on the flesh firmness because the penetration speed was faster than the Rheoner.

A TA.XTplus texture analyzer, which can obtain both mechanical and acoustic responses simultaneously, was used to examine the flesh texture of apple fruit in previous studies (Costa et al., 2011, 2012; Piazza and Giovenzana, 2015). Costa et al. (2011) suggested that the mechanical profile alone is not sufficient to select a desirable crispy apple. They used the instrument on 86 different apple cultivars to characterize their textural performance. They observed that 'Granny Smith' and 'Coop 39' had higher acoustic responses, although the mechanical response of 'Coop 39' was clearly much firmer than that of 'Granny Smith'. Similarly, our results showed that the mechanical profiles were distinguishable from the acoustic profiles (Table 2); 
'Selection A' had the highest maximum acoustic pressure value $(68.8 \mathrm{~dB})$ in the radial direction, despite its average firmness of $60.1 \mathrm{~N}$, of 18 cultivars and selections (Fig. 6). The textural characteristic of 'Selection A' was evaluated as high crunchiness. In the present study, 'Shinano Gold' also showed a relatively high degree of acoustic pressure. In addition, consumer preference analysis has shown that consumers in the EU tend to like 'Shinano Gold' owing to its high quality flesh texture (Nakamura and Maruyama, 2008). 'Selection A' and 'Shinano Gold' were selected by breeders using a sensory test because they were crunchy owing to moderate firmness and high juiciness. Thus, the acoustic data during the penetration test were important for evaluating flesh texture. The maximum acoustic response was positively correlated with the $\mathrm{CI}$ values obtained from TA.XTplus in both directions of the 18 cultivars and selections (Table 2). This means that a larger amplitude of mechanical force resulted in a high acoustic response value. In addition, there was a significant correlation between acoustic parameters and sensory test results in this study (Table 3), implying that the acoustic parameters may be useful in the objective evaluation of textural properties instead of each breeder's trained subjective evaluations.

Piazza and Giovenzana (2015) and Costa et al. (2012) also reported that the acoustic emission is a useful parameter not only for evaluating flesh texture at the harvest stage, but also after cold storage. Costa et al. (2012) showed that some cultivars, including 'Fuji' that is well known for having long storage ability, had high degrees of acoustic pressure after long cold storage. Additionally, 'Shinano Gold' showed a relatively high number of acoustic peaks and mean acoustic pressure. Their results may partially explain why 'Shinano Gold' has long term storage ability when subjected to 1-MCP treatment (Naramoto, 2019).

We observed year-to-year CI value correlations in 18 apple cultivars and selections, although the absolute CI values in some cultivars and selections were different depending on the year. These results suggest that the CI value is a genetic characteristic of each cultivar. It has been shown that traits related to fruit texture, including flesh firmness, have moderate to high broad sense heritability (Ben Sadok et al., 2015; Tazawa et al., 2020). In addition, Di Guardo et al. (2017) reported that the mechanical properties and acoustic response obtained by the TA.XTplus analyzer were genetically controlled, and that two quantitative trait loci (QTLs) are associated with the latter. The CI value may be controlled under the same QTLs found by Di Guardo et al. (2017), as it was significantly correlated with acoustic response in this study. However, Kunihisa et al. (2014) reported novel QTLs related to apple fruit quality traits were identified in their study, although many QTLs corresponded to those of other studies using European or New Zealand cultivars. Therefore, textural properties such as those of 'Selection B' may be controlled by a different genetic background than those reported in previous studies. Further studies are required to understand whether there is an association between the CI value and the genetic background.

\section{Directional differences in apple flesh specimens}

Khan and Vincent $(1993 \mathrm{a}, \mathrm{b})$ reported that most of the apple cortex consists of radially elongated cylindrical cells radiating outwardly end-to-end in distinct columns, so that radial or tangential directional differences in apple flesh parenchyma must be considered to evaluate the mechanical properties of apple flesh. The cells and intercellular spaces arrange in a similar orientation from the surface to the center. The spaces become radially elongated and lie between the radial columns. They can be up to around $3 \mathrm{~mm}$ long and $50-100 \mu \mathrm{m}$ in diameter (Khan and Vincent, 1993b), and the wedge penetration test and taste panel test showed that apple flesh was split much more easily along the cell column (radial) than at a right angle to the cell column (tangential) (Khan and Vincent, 1993b). Kohyama et al. (2017) revealed that the mechanical value and acoustic response peak number obtained from the tangential directions were higher than those obtained from the radial directions. In the present study, the maximum value of the mechanical properties in the tangential direction tended to be slightly higher compared to that of the radial direction. The sensory test did not allow for directional differences of the specimens, but we observed that the correlation coefficient of the sensory test results and the CI value in the tangential direction were slightly higher than those in the radial direction from the Rheoner (Table 3). Therefore, physical properties in the tangential direction may be more related to the sensory qualities of apple flesh than those in the radial direction.

In conclusion, we examined the flesh texture of apple cultivars using instruments. The results suggested that the CI value and acoustic response were suitable for explaining the variation in textural properties, especially crunchiness. It may be possible to categorize textural characteristics such as crispness, crunchiness and fibrousness that affect palatability using different parameters including firmness, CI and the acoustic response. We have been developing crossed populations using selections with high CI values and acoustic responses. Further studies are in progress to identify seedlings that produce apple flesh with crispness and crunchiness and for the objective analysis of the flesh texture of apples using segregated seedlings.

\section{Acknowledgements}

We would like to thank Mr. K. Yamato and Mr. T. Osawa for their technical assistance.

\section{Literature Cited}

Ben Sadok, I., A. Tiecher, D. Galvez-Lopez, M. Lahaye, P. 
Lasserre-Zuber, M. Bruneau, S. Hanteville, R. Robic, R. Cournol and F. Laurens. 2015. Apple fruit texture QTLs: year and cold storage effects on sensory and instrumental traits. Tree Genet. Genomes 11: 119. DOI: 10.1007/s11295015-0947-x.

Brown, S. K. and K. E. Maloney. 2013. An update on apple cultivars, brands and club-marketing. NY Fruit Quarterly 21: 310 .

Brown, S. K. and K. E. Maloney. 2018. Update on new apple varieties, managed varieties and clubs. NY Fruit Quarterly 26: $5-10$

Chang, H. Y., Z. M. Vickers and C. B. S. Tong. 2018. The use of a combination of instrumental methods to assess change in sensory crispness during storage of a "Honeycrisp" apple breeding family. J. Text. Stud. 49: 228-239.

Costa, F., L. Cappellin, M. Fontanari, S. Longhi, W. Guerra, P. Magnago, F. Gasperi and F. Biasioli. 2012. Texture dynamics during postharvest cold storage ripening in apple (Malus $\times$ domestica Borkh.). Postharvest Biol. Technol. 69: 54-63.

Costa, F., L. Cappellin, S. Longhi, W. Guerra, P. Magnago, D. Porro, C. Soukoulis, S. Salvi, R. Velasco, F. Biasioli and F. Gasperi. 2011. Assessment of apple (Malus $\times$ domestica Borkh.) fruit texture by a combined acoustic-mechanical profiling strategy. Postharvest Biol. Technol. 61: 21-28.

Di Guardo, M., M. C. A. M. Bink, W. Guerra, T. Letschka, L. Lozano, N. Busatto, L. Poles, A. Tadiello, L. Bianco, R. G. F. Visser, E. Van De Weg and F. Costa. 2017. Deciphering the genetic control of fruit texture in apple by multiple family-based analysis and genome-wide association. J. Exp. Bot. 68: 1451-1466.

Evans, K. M., B. H. Barritt, B. S. Konishi, L. J. Brutcher and C. F. Ross. 2012. "WA 38" apple. HortScience 47: 11771179.

Horie, H., H. Ito, K. Ippoushi, K. Azuma and I. Igarashi. 2004. Evaluation of the physical quality of the mesocarp of cucumber fruit. Hort. Res. (Japan) 3: 425-428 (In Japanese with English abstract).

Ichikawa, E., T. Fukuda, T. Funabashi, K. Naramoto, T. Maejima, H. Tamai and H. Komatsu. 2018. Effects of temperatures attributed to global warming in Nagano prefecture on tree growth and fruit quality of 'Fuji' apples. (Part1) Tree growth and fruit quality of 'Fuji' apples after four years of planting. Hort. Res. (Japan) 17 (Suppl. 1): 55 (In Japanese).

Kanamaru, K., T. Maejima, H. Komatsu, A. Usuda, T. Haniuda, T. Shimazu and K. Izumi. 2016. New apple cultivar 'Shinano Hoppe'. Nagano Pref. Fruit Tree Expt. Sta. Bull. 7: 8-14 (In Japanese with English abstract).

Khan, A. A. and J. F. V. Vincent. 1993a. Compressive stiffness and fracture properties of apple and potato parenchyma. J. Text. Stud. 24: 423-435.

Khan, A. A. and J. F. V. Vincent. 1993b. Anisotropy in the fracture properties of apple flesh as investigated by crackopening tests. J. Material. Sci. 28: 45-51.

Kohyama, K., S. Kasai, H. Hayakawa and T. Watanabe. 2017. Mechanical and acoustic analysis for texture of apple fruit considering structural anisotropy. [Translated from
Japanese]. Food Sci. Technol. Re. 64th (Abstr.).

Komatsu, H. 2018. Breeding of 'Shinano Sweet' and 'Shinano Gold' apples and development of their management techniques to stably produce high-quality fruits. Hort. Res. (Japan) 17: 269-277 (In Japanese with English abstract).

Komatsu, H., A. Usuda and T. Haniuda. 2019. Apple cultivar 'Shinano Gold/YELLO ${ }^{\mathrm{TM}}$ '-A yellow, mid-season apple from Nagano, Japan. Nagano Pref. Fruit Tree Expt. Sta. Bull. 8: $1-6$.

Komatsu, H., A. Usuda, T. Haniuda, H. Yamashita and T. Miyazawa. 2000. A new apple cultivar 'Shinano Gold'. Hort. Res. (Japan) 69 (Suppl. 1): 224 (In Japanese).

Kunihisa, M., S. Moriya, K. Abe, K. Okada, T. Haji, T. Hayashi, H. Kim, C. Nishitani, S. Terakami and T. Yamamoto. 2014. Identification of QTLs for fruit quality traits in Japanese apples: QTLs for early ripening are tightly related to preharvest fruit drop. Breed. Sci. 64: 240-251.

Luby, J. J. and D. S. Bedford. 1992. Honeycrisp apple. Minnesota Reports 64: 225.

Masumoto, N., H. Ura, A. Eshima and H. Ikeda. 2018. Quantifying persimmon flesh texture using crispness index and maximum stress. Fukuoka Agr. For. Res. Cent. Bull. 4: 109-113 (In Japanese with English abstract).

Nakamura, T. 2010. An evaluation of domestic consumers for domestic apples: at the background of the production trend of the internationally famous brands. Kyoei Univ. Bull. 8: 19-36 (In Japanese with English abstract).

Nakamura, T. and A. Maruyama. 2008. The strategy for promoting the export of yellow apples approved by EUREPGAP: As a result of the questionnaires at messe Berlin FRUIT LOGISTICA 2007. Food System Res. 15: 11-24 (In Japanese with English abstract).

Naramoto, K. 2019. Cold storability and optimum condition of fruit for long storage in 'Shinano Gold' cultivar [Translated from Japanese]. JAPR J. 52: 685-687 (In Japanese).

Piazza, L. and V. Giovenzana. 2015. Instrumental acousticmechanical measures of crispness in apples. Food Res. International 69: 209-215.

Sugiura, T., H. Ogawa, N. Fukuda and T. Moriguchi. 2013. Changes in the taste and textural attributes of apples in response to climate change. Sci. Reports 3: 2418. DOI: 10.1038/srep02418.

Tazawa, J., T. Kudo, H. Kudo, K. Sakamoto, Y. Hatsuyama, T. Ishizuka, K. Nashima and M. Yamada. 2020. Genetic and environmental variation for flesh firmness in 19 apple cultivars. Hort. Res. (Japan) 19 (Suppl. 1): 239 (In Japanese).

Yoshikawa, Y., H. Horie, M. Sugiyama and Y. Sakata. 2009. Quantifying cucumber fruit crispness by mechanical measurement. Breed. Sci. 59: 139-147.

Zdunek, A., J. Cybulska, D. Konopacka and K. Rutkowski. 2010a. New contact acoustic emission detector for texture evaluation of apples. J. Food Eng. 99: 83-91.

Zdunek, A., D. Konopacka and K. Jesionkowska. 2010b. Crispness and crunchiness judgment of apples based on contact acoustic emission. J. Text. Stud. 41: 75-91. 